\title{
Effect of Hydroxyapatite Nano Rods on Sinterability and Bioactivity of Fe-14Mn-6Si Alloy Prepared By Powder Metallurgy
}

\author{
M F Zawrah ( $\square$ mzawrah@hotmail.com ) \\ National Research Centre https://orcid.org/0000-0001-5172-7304 \\ Ibrahim M. Hassab Allah \\ Assuit university \\ Ayman R. Abdellah Awad \\ Sohag University \\ Moataz Bellah H. Ata \\ Sohag University
}

Original Research

Keywords: Fe-14Mn-6Si/HA composites, Powder metallurgy, Sintering, Hardness, Bioactivity

Posted Date: February 10th, 2021

DOI: https://doi.org/10.21203/rs.3.rs-173168/v1

License: (a) (i) This work is licensed under a Creative Commons Attribution 4.0 International License. Read Full License 


\section{Abstract}

Recently, there is a great of industrial interest on the production of biodegradable metal/ceramic composites. The casted Fe-Mn-Si alloys prepared by casting tools have low biodegradable rate; so it is important to seek a method as powder metallurgy (PM) to prepare porous bodies with increased biodegradability. Moreover, the addition of hydroxyapatite (HA) nano rods to that alloy increases its bioactivity and forms composite with improved properties. In the present study, Fe-14Mn-6Si/HA composites were prepared by PM and sintered at different temperatures, i.e. 1100,1150 and $1200^{\circ} \mathrm{C}$. Also, the effect of HA nano-rods content on the composite properties (physical properties, microstructure and micro hardness) and bioactivity were studied. The results revealed that bulk density increased with increasing sintering temperature up to $1150^{\circ} \mathrm{C}$; then decreased at $1200^{\circ} \mathrm{C}$. Also, the bulk density increased with increasing the HA content. Moreover, the hardness of the sintered composites increased with increasing sintering temperature and HA amount. The maximum hardness values were $1293 \& 1792 \mathrm{MPa}$ for the specimens which contain $8 \% \mathrm{HA}$ and sintered at 1150 and $1200^{\circ} \mathrm{C}$, respectively. The bioactivity of the prepared composites increased with increasing HA amount. The highest bioactivity was for the composite that contains 8 wt. \% HA.

\section{Introduction}

Composites of iron alloys/hydroxyapatite are interesting biodegradable implants since their individual components have several advantages. It is well known that the Fe-Mn-Si alloys that have high Mn content $\geq 20 \mathrm{wt} . \%$ are characterized by shape-memory effect (SME) owing to the reversible phase-transition between the face-centered cubic austenite and hexagonal close-packed martensite [1-5]. This characteristic makes these alloys are interesting for civil applications like pipe joint, dampers and other technological applications [68]. Early 80 s, Sato et al. $[9,10]$ reported on the shape memory effect (SME) of these alloys. Since then, these materials have been widely studied and received significant consideration due to their low-cost, good workability, weldability, and worthy machinability properties [11, 12]. Recently, it has been reported that Fe-Mn-Si alloys are promising candidate as degradable biomaterials owing to their high cell viability, worthy mechanical properties and acceptable degradation rate $[13,14]$. Also, provisional biomedical-devices like cardiovascular-stents and bone fixation plates have been considered as prospective uses of Fe-Mn-Si alloys owing to their sound biodegradability, great biocompatibility and mechanical properties [15-19]. However they have low biodegradable rate due to their dense structure. So, the preparation of these alloys by powder metallurgy (PM) can overcome the lower degradation rate since PM has the ability to prepare porous alloys with controlled porosity. Moreover, the incorporation of hydroxyapatite in this alloys to form new composites, might also increase the bioactivity and other properties of these composites.

Generally, the addition of bioceramic nanoparticles to the Fe-Mn-Si alloys leads to extra improving of the biodegradability and biocompatibility as well as can form a composite with developed properties for commercial purposes. Hydroxyapatite (HA) is the most famous biomaterials which can form good composite when added to Fe-Mn-Si alloys. It is thermo-dynamically the most stable phase in physiological conditions and has the capability to chemically-bond directly to the bone owing to its similarities with composition and structure of bone- and tooth-minerals. It doesn't display any cytotoxic effect but it exhibits outstanding biocompatibility with hard-tissues, skin and muscle-tissues [20]. Furthermore, it shows substantial applications in other fields as catalyst, sensor, and optical applications, etc. [21] Rodriguez-Lorenzo et al. [22] reported on the synthesis of hydroxyapatite by precipitation method. The material prepared was stable up to $1200^{\circ} \mathrm{C}$ and when sintered between $900-1200^{\circ} \mathrm{C}$ showed dense HA bodies. The optimum sintering temperature was $1100^{\circ} \mathrm{C}$; it gave higher mechanical properties with balanced ratio between the total pore area and the average grain size. Over $1100^{\circ} \mathrm{C}$, the porosity and density might be increased due to the phase transformation and decomposition of $\mathrm{HA}$ into another phases. This indicates that the $\mathrm{HA}$ sintered quickly when it is only exist. The presence of pores facilitates the formation of interfacial bond and adhesion between HA or metallic implants and living tissues; consequently develops the strength. [23-26]. When the pore size is very large or very small, the cell cannot spread in the scaffold and cannot form networks [27]. On the other hand, the suitable large porosity increases the surface-area which produces high cell-seeding effectiveness, movement and neovascularization [28]. Pang and Bao synthesized nano size HA powder by chemical precipitation using $\mathrm{CaCl}_{2}$ and ammonium hydrogen phosphate [29].

There are several approaches for preparing alloys and composites as ingot metallurgy (IM) and powder metallurgy (PM) [30-35]. PM technique has some benefits like cost-effectiveness, high production-rate, can produce complex shapes, and can produce laminated bodies by different layers of powders. Mechanical alloying (MA) is the most famous technique in PM for preparing alloys and composites. From this method, controlled grain size, fine microstructure and homogenous chemical-composition can be accomplished in solid state [36], therefore avoiding the disadvantages of IM method.

The present work focuses on the preparation of Fe-14Mn-6Si/HA composites by PM technique. The study of sinterability, microstructure, hardness and bioactivity are the main objectives of the present study. 


\section{Materials And Experimental Methods}

\subsection{Materials}

Pure Fe-14Mn-6Si alloy was supplied by Algoumhoria Company for Chemicals Trade and Medicals, Cairo, Egypt. The hydroxyapatite nano rods was synthesized in the nano laboratory at National Research Center, Egypt, according the method described elsewhere [37]. Paraffin wax, stearic acid, and ethanol alcohol were also supplied by Algoumhoria Company for Chemicals Trade and Medicals. The purity and physical properties of utilized powders are illustrated in the Table 1.

Table 1

Purity and physical properties of Fe.14Mn.6Si alloy and HA powders

\begin{tabular}{|llllll|}
\hline Element/oxide & Purity, $\%$ & Particle size, $\boldsymbol{\mu m}$ & Particle shape & Density, $\mathbf{g} / \mathbf{c m}^{\mathbf{3}}$ & Melting point, ${ }^{\circ} \mathrm{C}$ \\
\hline Fe & 99.5 & 74 & spherical & 7.874 & 1538 \\
\hline Mn & 99.3 & 44 & flake & 7.21 & 1246 \\
\hline Si & 99.9 & 44 & spherical & 2.33 & 1410 \\
\hline HA & 99.8 & $0.025-0.10$ & rod & 3.18 & 1670 \\
\hline
\end{tabular}

\subsection{Experimental procedures}

The phase composition of Fe-14Mn-6Si alloy and HA was investigated by x-ray diffraction. X-ray diffractometer type Philips-PW1710 with Cu-Ka radiation of $\lambda=1.541838 \AA$ was utilized. The XRD scanning was between $20^{\circ}-90^{\circ}$, with a step interval of $0.02^{\circ}$ and a scan rate of $2 \%$ min. On the other hand, the morphology of HA nano rods was examined by transmission electron microscope type JOEL JSM-1230.

In the present work, powder metallurgy process was utilized to fabricate the designed composites through the pressure less sintering technique. Four different composite batches were designed and prepared from Fe-14Mn-6Si alloy with 0, 2, 4 and 8wt.-\% hydroxyapatite. Table 2 illustrates the batch composition of designed composites.

Table 2

Batch composition of designed composites

\begin{tabular}{|lll|}
\hline Sample no. & Mass, \% & \\
\cline { 2 - 3 } & Fe-14Mn-6Si & HA \\
\hline A & 100 & 0.0 \\
\hline B & 98 & 2 \\
\hline C & 96 & 4 \\
\hline D & 92 & 8 \\
\hline
\end{tabular}

The appropriate quantities of Fe-14Mn-6Si and HA powders were weighted and mixed in electric V-mixer for 12 hours. After mixing, the powder was compacted in stainless steel cylindrical die using a hydraulic press machine type (Matest Italy/C055d) under pressure of 500 MPa. Samples with $8 \mathrm{~mm}$ diameter and $4 \mathrm{~mm}$ height were produced. The pressed specimens were sintered in a tube furnace type GSL $1600 X$ at 1100,1150 and $1200^{\circ} \mathrm{C}$ with continuous stream of Argon inert gas from the initial to the final stage of sintering. The samples were first heated at a rate of $10^{\circ} \mathrm{C} / \mathrm{min}$. up to $1100^{\circ} \mathrm{C}, 1150^{\circ} \mathrm{C}, 1200^{\circ} \mathrm{C}$, and kept for $120 \mathrm{~min}$. Then, the furnace was turned off and the sintered specimens were cooled over $8 \mathrm{~h}$ in the furnace [38-42]. Figure 1 shows the images of sintered specimens.

The physical properties in terms of bulk-density (BD) and apparent porosity (AP) were tested by liquid-displacement method according to Archimedes rule. The BD and AP were calculated by the following equations:

$$
\text { Apparent porosity }=\frac{\mathrm{Ws}-\mathrm{Wd}}{\mathrm{Ws}-\mathrm{Wn}} \times 100
$$$$
\text { Bulk density }=\frac{\mathrm{Wd}}{\mathrm{Ws}-\mathrm{Wn}} \times \rho \mathrm{d}
$$ 
where: Ws is the weight of sample saturated by Xylene for $1 \mathrm{~h}$ under vacuum, $\mathrm{Wd}$ is the weight of dry sample, $\mathrm{Wn}=$ weight of the immersed sample in the Xylene and suspended in air, and $\rho d$ is the Xylene density [43]. The theoretical density was calculated by rule of mixture then used in calculation of relative density.

X-ray diffraction technique was employed to identify the phase composition of the composites sintered at different temperatures. Before examining the microstructure of sintered composites, all surfaces of the samples together with the edges were wet ground using 120 , 220,320, 600, 1000, 1200 and 2000, grit silicon carbide papers by standard grinding and polishing technique using a machine model Buhlertm. Then, these specimens were cleaned in distilled water and polished with diamond past of $6 \mu \mathrm{m}$ to get a bright mirror finish for the last step. Finally, these samples were degreased with acetone. After drying, these samples were kept in Ziplock bags. The microstructure was examined by scanning electron microscope model "Jeol 5400" linked EDS detector.

Micro hardness is a nondestructive technique that can represent the final strength of material surface and it requires no especial specimen shape. In the present study, Vickers micro hardness measurements of sintered specimen were carried out using nova 240 micro hardness tester (NOVA TEST made in Japan Co., Ltd.) with a contact load of $10 \mathrm{gm}$.f up to $2 \mathrm{~kg}$.f. The micro hardness determination was conducted according to ASTM E384-11 standard test method at a temperature of $25 \pm 3^{\circ} \mathrm{C}$ using a diamond indenter with a steady load.

The bioactivity was studied by immersing the sintered composites in simulated body fluid (SBF) for one month, and then the surface of immersed composites was examined by scanning electron microscope attached with EDAX unit for qualitative analysis. SBF was prepared according to the method described elsewhere [44].

\section{Results And Discussion}

\subsection{Charcterstics of synthsized hydroxyapatite and Fe-14Mn-6Si powdres}

Figure 2 shows XRD patrens of synthsized hydroxyapatite powder (nano rods). As indicated from the pattern, well crystalline hexagonal $\mathrm{Ca}_{10}\left(\mathrm{PO}_{4}\right)_{6}(\mathrm{OH})_{2}$ phase is detected and no peaks for other materials are appeared in the patern. The main three peaks are equivalent to $\mathrm{d}$ spacing $2.8068,2.7788 \& 2.7099$. The apperence of broad peaks refers to the formation of small particle size. TEM iamges of prepared hydroxyapatite powder are desplayed in Fig. 3 with two magnefications. It is apeared that the particles are homogenous in shape but different in sizes. The particles have rod-like shape with length range $20-80 \mathrm{~nm}$ and daimter of bout $5-10 \mathrm{~nm}$. The rod-like shape is formed due to the interconnction of $\mathrm{Ca}^{2+}$ with $\mathrm{PO}_{4}{ }^{3-}$ and $\mathrm{OH}^{-}$ions. This kinde of morphology is promising for imporving the mehanical and bioactivity of hydroxyapaptite-including composite. Figure 4 shows XRD patern of Fe-14Mn-6Si alloy powder. As indicated from the pattern, the alloy composed mainly of component of alloy $\mathrm{Fe}, \mathrm{Mn}$ and $\mathrm{Si}$. Furthermore, it can be seen that the diffraction peaks are intense and sharp owing to their higher crystallinity.

\subsection{Charcterstics of sintered Fe-14Mn-6Si/HA composites}

\subsubsection{Bulk desity and apparent porosity of sintered composites}

In this section, it is important to achieve the suitable sintering temperature to obtain composites with good properties. The green compacted specimens obtained after compaction operation are friable and cannot be used. In order to make them usable ones, they must undergo sintering operation. It is well-known that the sintering can be defined as the bonding of adjacent surfaces of particles in a mass of metal powder by heating. The time of exposure to the temperature as well as the rate of heating and cooling should be controlled. The heating should be gradual since fast heating will cause sudden vaporization and could result in the disintegration of the compact. The sintering temperature is normally below the melting points of all powder constitutes. The sintering temperature for powder varies over a range ( 0.7 to 0.9 times the melting point), but there is usually an optimum maximum sintering temperature for a given set of conditions beyond which no gain is obtained. Table 3 illustrates the bulk density, relative density and apparent porosity of composites sintered at 1100,1150 and $1200^{\circ} \mathrm{C}$. All the bulk density values are in a narrow range $\left(4.77-5.36 \mathrm{~g} / \mathrm{cm}^{3}\right)$; this is due to the almost similarity of phase composition for all sintered composites. For all composites except composite $\mathrm{D}$, the bulk density increases with increasing the sintering temperature and reaches its maximum values at $1150^{\circ} \mathrm{C}$ then decreases at $1200^{\circ} \mathrm{C}$. For composite $\mathrm{D}$, the bulk density increases with increasing sintering temperature and reaches its maximum value at $1200^{\circ} \mathrm{C}$. This might be attributed to the increase of diffusion rate of grains, decreasing of the number of pores and decreasing relatively the grain growth. The relative density trend goes with the bulk density one. On the other hand, the apparent porosity goes in opposite trend for all composite batches. Generally, with rising the sintering temperature, the grins' diffusion and the grains interaction increase with the chance of liquid phase formation. After addition of nano hydroxyapatite, this leads to decreasing the apparent porosity and increasing the bulk density of sintered composites due to the closing of the pores by the nano particles with the probability of formation low melting phases which can also close the pores. Although the addition 
of HA nanoparticles decreases the porosity, it still within appropriate range for biomedical implants. The increasing of porosity at high sintering temperature is due to the decomposition of hydroxyapatite into tricalcium phosphate, $\mathrm{CaO}$ and $\mathrm{H}_{2} \mathrm{O}$. It has been reported that the decomposition of $\mathrm{HA}$ begins in the range $1050-1100^{\circ} \mathrm{C}$ [37].

Table 3

Bulk density and apparent porosity of prepared composites sintered at different temperatures

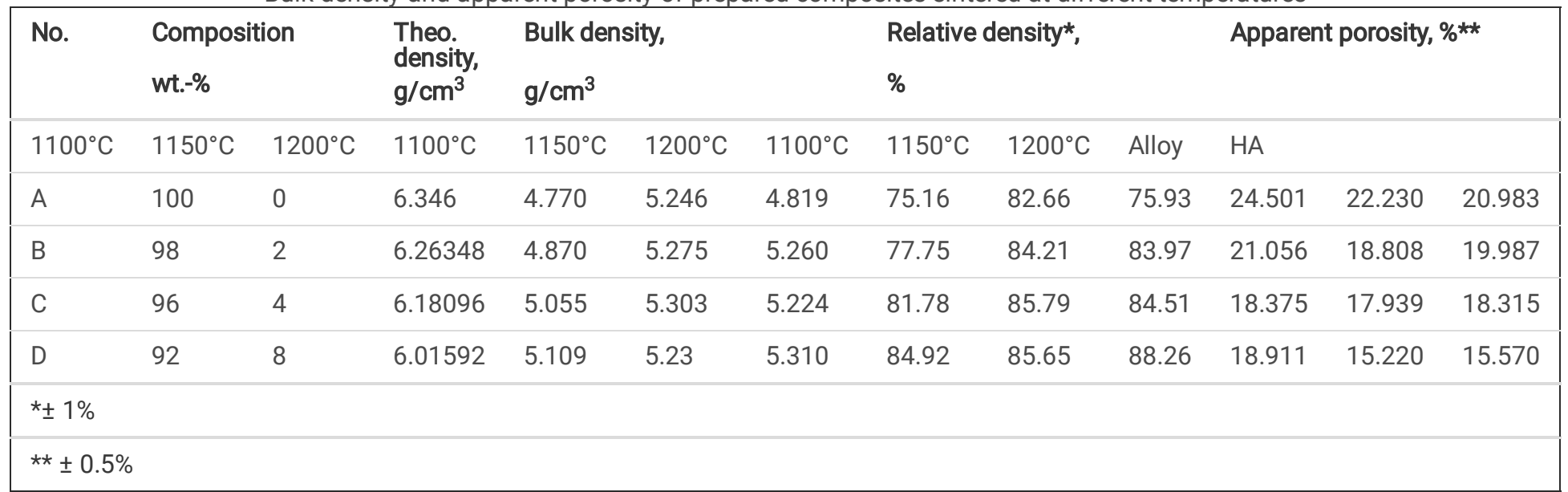

\subsubsection{Phase composition of sintered composites}

XRD paterns of Fe-14Mn-6Si/HA composites sintered at $1150^{\circ} \mathrm{C}$ are shown in Fig. 5 . It is indicated from the patterns that the main peaks of a-Fe are appeared. $\mathrm{Mn}$ and Si phases are dissolved in a-Fe structure as solid solutions. New peaks for hydroxyapatite and tricalcium phosphate are detected in the patterns of composites that contain 4 and $8 \%$ hydroxyapatite. Their amounts are higher in case of addition $8 \%$ hydroxyapatite. The appearance of tricalcium phosphate is due to the partially dissociation of hydroxyapatite at $1150^{\circ} \mathrm{C}$.

\subsubsection{Microstructure of sintered composites}

Figures $6 \& 7$ show SEM images of Fe-14Mn-6Si alloy and Fe-14Mn-6Si/8\%HA sintered at $1150^{\circ} \mathrm{C}$, respectively. It is worth to mention that the higher cold-pressing load leads to interconnecting the particles mechanically and forms high grain boundaries. In the present study, the samples were pressed at higher load, i.e 500MPa, to improve the microstructure. As indicated from the microstructure, the main metal (iron alloy) phase is predominant (bright color). Its quantity is higher in case of pure Fe-14Mn-6Si (Fig. 6) alloy than Fe-14Mn-6Si/8\%HA composite (Fig. 7). Homogenous microstructures with excellent distribution for the reinforcement phases are appeared. Some metals and intermetallic phases are appeared as fused compacted areas between the iron alloy matrix grains. Also, the iron matrix includes some pores, some precipitated phases come from the formed liquid phases (second phase) and some phases formed due to the partially oxidized alloy. The grain sizes of sintered-alloy and composite are very fine with the range between $\leq 1 \mu \mathrm{m}$ and few microns. This might be effectively reflected on the hardness values. The presence of some parallel lines intersecting the whole grains indicates the existence of some amounts of $\varepsilon$-martensite phase. The addition of hydroxyapatite leads to decreasing the amount of pores and increases the amount of second phases as well as partially oxidized alloy phases. Also, the increase of sintering temperature leads to increase the direct contact between the grains and forms locked pores with grain growth. This makes a good homogenous and dense microstructure. Hydroxyapatite reinforcement particles affect directly the contacts between the Fe-14Mn-6Si matrix grains, forms closed pores with grain growth.

\subsubsection{Micro hardness of sintered composites}

It is well-known that the factors which control the enhancement of hardness of composite are attaining improved microstructure with well distributed reinforcement, refining the grain size and development of low-pores microstructure. Table 4 and Fig. 8 represent the values of microhardness for Fe-14Mn-6Si/HA composites sintered at various temperatures. It is appeared that the hardness increases with increasing both amount added of $\mathrm{HA}$ and sintering temperature except the composite $\mathrm{B}$ in the which the hardness increases up to $1150^{\circ} \mathrm{C}$ then decreases when sintered at $1200^{\circ} \mathrm{C}$. The maximum value of the hardness is obtained for the composite that contains 8 wt.\% HA and sintered at $1200^{\circ} \mathrm{C}$. The distribution of harder HA nano rods in the matrix lead to improving the hardness of the composites than the pure sintered alloy. The development of low-pore microstructure after sintering at higher temperature and after addition of harder HA nanoparticle lead to the increasing the hardness of the sintered composites. Also, the nano rods can form interlock between the matrix grains and then improve all mechanical properties 
Table 4

Micro hardness values of Fe-14Mn-6Si/HA composites sintered at different temperatures

\begin{tabular}{|c|c|c|c|c|c|}
\hline \multirow[t]{2}{*}{ No. } & \multicolumn{2}{|c|}{ Composition, wt.\% } & \multicolumn{3}{|c|}{$\begin{array}{l}\text { Micro hardness (MPa) } \\
\pm 5\end{array}$} \\
\hline & alloy & HA & $1100^{\circ} \mathrm{C}$ & $1150^{\circ} \mathrm{C}$ & $1200^{\circ} \mathrm{C}$ \\
\hline A & 100 & 0 & 808.70 & 825.4 & 877.0 \\
\hline B & 98 & 2 & 946.70 & 1165 & 887.6 \\
\hline C & 96 & 4 & 1004.00 & 1266 & 1369 \\
\hline D & 92 & 8 & 1018.99 & 1293 & 1792 \\
\hline
\end{tabular}

\subsubsection{Bioactivity of sintered composites}

Fe-Mn-Si/HA composites are considered as interesting materials owing to their excellent mechanical properties, good biocompatibility and degradability in the human body, so they can apply as impermanent implants such as cardiovascular stents and bone-fixation devices (Ex. plates, screws and nails). The biodegradability properties of these composites can facilitate the prevention of chronic-inflammation, thrombosis, in-stent restenosis [7, 8] or even after elimination of the implants [13, 14], in comparison with the implants having corrosion resistance like stainless-steels $316 \mathrm{~L}$ and alloys that contain $\mathrm{Ti}$ and $\mathrm{Co}-\mathrm{Cr}[9-10,45,46]$.

The typical microstructure and corresponding EDAX spectra of Fe-14Mn-6Si/HA composites after immersion in SBF for one month are shown in Figs. 9-12. As mentioned before, the main phase in the microstructure is the iron alloy phase (bright color) surrounded by pores, precipitated second phase and hydroxyapatite grains. The amount of iron alloy phase decrease with increasing the HA amount. After the immersion of sintered composite in SBF for 30 days, the microstructure feature is relatively changed. Beside the aforementioned phases and microstructure features, layer of calcium/phosphorous is formed on the surface of immersed composites. Its amount increases with increasing the amount of added HA indicating the higher bioactivity of the composites than the Fe-Mn-Si alloy. These results are confirmed by the results of EDAX analyses presented in Figs. 9-12d. The peak intensity of calcium and phosphorus increases with increasing the amount of HA in the composites. The appearance of oxygen peaks comes from the corrosion/oxidation of the alloy during the degradation process and also comes from the added HA. Also, new large pits are observed on the surface of the composites as detected in all microstructure images. Their areas increase with increasing the amount of AH. These harshly local large pits are weak sites for crack initiation. The degradation of these composites can be explain as follow; after immersion in SBF, the corrosion process proceeds in four stages; i.e. initial corrosion reaction, formation of hydroxide layer, formation of pits and formation of calcium/phosphorus layer. Firstly, $\mathrm{Fe}^{2+}, \mathrm{Mn}^{2+}, \mathrm{Si}^{4+}$ and $\mathrm{OH}^{-}$are formed after soaking in $\mathrm{SBF}$ solution. Secondly, $\mathrm{Fe}^{2+}$ reacted with $\mathrm{OH}^{-}$to form insoluble hydroxides which can form after series of reactions a mixture $\mathrm{Fe}_{2} \mathrm{O}_{3}, \mathrm{Fe}_{3} \mathrm{O}_{4}$ and $\mathrm{FeO}$ layers. Thirdly, during the progress of degradation, chloride ion in SBF reacts with $\mathrm{Fe}^{2+}$ to form iron chloride, which is further hydrolyzed by water and created hydroxide and free hydrochloric acid which contributes in the growing of the localized pits. Finally, a new biocompatible layer comprised of calcium/phosphorus is formed on the surface of the composites [47]. This means that at the starting of degradation, the surface of composite is coated by bone-cells since the porous composite supports bone-cell adhesion and proliferation. Throughout the degradation, the bone tissues develop well into the pores and renew the bone, increasing the strength of the composite. Finlay, the pores are totally occupied with renewed bone at the end of the degradation [48].

\section{Conclusions}

In conclusion, Fe-14Mn-6Si/HA composites have been successfully prepared by powder metallurgy technique and sintered at different temperatures for biomedical applications. According the results of physical properties, the sintering temperature $1150^{\circ} \mathrm{C}$ was selected as the optimum sintering temperature. The achieved results can be summarized as follow:

1. The bulk density of sintered composites was increased with increasing $\mathrm{HA}$ content and sintering temperature up to $1150^{\circ} \mathrm{C}$ then decreased after sintering at $1200^{\circ}$ On contrast, apparent porosity went into opposite trend.

2. The micro hardness of sintered composites was enhanced with rising the sintering temperature and HA content due the reinforcement of the matrix. The maximum hardness ( $1293 \& 1792 \mathrm{MPa}$ ) was obtained for the composites that contain $8 \% \mathrm{HA}$ and sintered at 1150 and $1200^{\circ} \mathrm{C}$, respectively. 
3. The incorporation of HA in the sintered composites improved the bioactivity. The bioactivity increased with increasing the HA content. Both of composite-components were necessary for the composites' properties.

\section{Declarations}

\section{Funding statement}

There are no funding sources

\section{Conflict of Interest}

The authors declare that there is no conflict of interest

\section{Author contributions}

Professor Zawrah planned and wrote the final article. Professor Ibrahim and Motaz Ata contributed in the supervision on the work and reviewing the first draft, while Mr Ayman Ramadan conducted the experiments and wrote the first draft

\section{Availability of data and material}

All available results were inserted in the article.

\section{Compliance with ethical standards}

The authors confirms that the article is Compliance with ethical standards

\section{Consent to participate}

'Not applicable'

\section{Consent for Publication}

'Not applicable'

\section{Acknowledgments}

'Not applicable'

\section{References}

1. Stanford, D.P. Dunne, Effect of Si on the reversibility of stress-induced martensite in Fe-Mn-Si shape memory alloys. Acta Mater. 58 (2010) 6752-6762.

2. Gebhardt, D. Music, D. Kossmann, M. Ekholm, I.A. Abrikosov, L.Vitos, J.M. Schneider, Elastic properties of fcc Fe-Mn-X (X = Al, Si) alloys studied by theory and experiment. Acta Mater. 59 (2011) 3145-3155.

3. Sato, E. Chishima, Y. Yamaji, T. Mori, Orientation and composition dependencies of shape memory effect IN Fe-Mn-Si alloys. Acta Metall. 32 (1984) 539-547.

4. Sato, Y. Yamaji, T. Mori, Physical properties controlling shape memory effect in Fe-Mn-Si alloys. Acta Metall. 34 (1986) 287-294.

5. Koyama, T. Sawaguchi, K. Tsuzaki, Si content dependence on shape memory and tensile properties in Fe-Mn-Si-C alloys. Mater. Sci. Eng. A 528 (2011) 2882-2888.

6. Sato, H. Kubo, T. Maruyama, Mechanical Properties of Fe-Mn-Si Based SMA and the Application. Mater. Trans. 47 (2006) 571.

7. Janke, C. Czaderski, M. Motavalli, J. Ruth, Applications of shape memory alloys in civil engineering structures-Overview, limits and new ideas. Mater. Struct. 38 (2005) 578-592.

8. Alam, M. Youssef, M. Nehdi, Can. J. Civ. Utilizing shape memory alloys to enhance the performance and safety of civil infrastructure: a review. Eng. 34 (2007) 1075-1086.

9. Sato, E. Chishima , K. Soma, and T. Mori, Shape Memory Effect in Gamma Reversible Epsilon Transformation in Fe-30Mn-1Si Alloy Single Crystals ,Acta Metall., 1982,30(6), p 1177-1183 
10. Sato, E. Chishima, Y. Yamaji, and T. Mori, Orientation and Composition Dependencies of Shape Memory Effect in Fe-Mn-Si Alloys, Acta Metall., 1984,32(4), p 539-547

11. Sato, T. Masuya, M. Morishita, S. Kumai, and A. Inoue, Strengthening of Fe-Mn-Si Based Shape Memory Alloys by Grain Size Refinement, Mater. Sci. Forum, 2000,327-328, p 223-226

12. Guenin, Shape Memory and Pseudo elastic Properties of Fe-Mn-Si and Ti-Ni Based Alloys ,J. Phys. IV Fr.,1997,7, p C5-467-C5-476.

13. Liu, Y. Zheng, L. Ruan, In vitro investigation of Fe30Mn6Si shape memory alloy as potential biodegradable metallic material. Mater. Lett. 65 (2011) 540-543.

14. Xu, M.A. Hodgson, P. Cao, A comparative study of powder metallurgical (PM) and wrought Fe-Mn-Si alloys. Mater. Sci. Eng. A 630 (2015) 116-124.

15. Xu, Z.; Hodgson, M.A.; Cao, P. A comparative study of powder metallurgical (PM) and wrought Fe-Mn-Sialloys. Mater. Sci. Eng. A 2015, $630,116-124$.

16. Xu, Z.; Hodgson, M.A.; Cao, P. Microstructure and degradation behavior of forged Fe-Mn-Si alloys. I. J. Modphys. B $2015,29,16$.

17. Liu, B.; Zheng, Y.; Ruan, L. In vitro investigation of Fe30Mn6Si shape memory alloy as potential biodegradable metallic material. Mater. Lett. 2011, 65, 540-543.

18. Xu, Z.; Hodgson, M.A.; Cao, P. Effect of Immersion in Simulated Body Fluid on the Mechanical Properties and Biocompatibility of Sintered Fe-Mn-Based Alloys. Metals 2016, 6, 309.

19. Xu, Z.; Hodgson, M.A.; Cao, P. Effects of Mechanical Milling and Sintering Temperature on the Densification, Microstructure and Tensile Properties of the Fe-Mn-Si Powder Compacts. J. Mater. Sci. Technol. 2016, 32, 1161-1170.

20. Suchanek, W., Yoshimura, M., Processing and properties of hydroxyapatite: Based biomaterials for use as hard tissue replacement implants. J. Mater. Res. 13(1998) [1] 94-117

21. Kanazawa, T.: Hydroxyapatite. In: Inorganic phosphate materials. Materials Sci-ence Monographs, Elsevier, Tokyo, 52 (1989) 30

22. Rodriguez-Lorenzo, L.M., Vallet-Regi, M., Ferreira, J.M.F.: Fabrication of hydroxyapatite bodies by uniaxial pressing from a precipitated powder. Biomaterials 22(2001) 583-588

23. J. Bartolo, C. K. Chua, H. A. Almeida, S. M. Chou, and A. S. Lim, "Bio-manufacturing for tissue engineering: Present and future trends," Virtual and Physical Prototyping, Vol 4. pp. 203, 2009.

24. J. Hollister, R. D. Maddox, and J. M. Taboas, "Optimal design and fabrication of scaffolds to mimic tissue properties and satisfy biological constraints," Biomaterials, Vol 23, pp. 4095, 2002.

25. C. Jones, C. H. Arns, D. W. Hutmacher, B. K. Milthorpe, A.P. Sheppard, and M. A. Knackstedt, "The correlation of pore morphology, interconnectivity and physical properties of 3Dceramic scaffolds with bone in growth," Biomaterials, Vol. 30,pp. 1440, 2009.

26. J. O'Brien, B. A. Harley, I. V. Llanas, and L. J. Gibson, "The effect of pore size on cell adhesion in collagen-GAG scaffolds," Biomaterials, Vol 26, pp. 433, 2005.

27. S. Van, G. Kerckhofs, M. Moesen, G. Pyka, J. Schrooten, and J. P. Kruth, "Micro-CT-based improvement of geometrical and mechanical controllability of selective laser melted Ti6Al4V porous structures," Materials Science and Engineering A, Vol. 528, no. 24, pp. 7423, 2011.

28. Kuboki, H. Takita, D. Kobayashi, E. Tsuruga, M. Inoue, and M. Murata, "BMP induced osteogenesis on the surface of hydroxyapatite with geometrically feasible and non-feasiblestructures: Topology of osteogenesis," Journal of Biomedical Materials Research, Vol. 39, pp. 190, 1998.

29. Suryanarayana, C., and Nasser Al-Aqeeli. "Mechanically alloyed nano " Progress in Materials Science 58, no. 4 (2013): $383-502$.

30. Nakano, P. J. Jacques, Effects of the thermodynamic parameters of the hcp phase on the stacking fault energy calculations in the Fe$\mathrm{Mn}$ and $\mathrm{Fe}-\mathrm{Mn}-\mathrm{C}$ systems. CALPHAD 34, 167 (2010)

31. C. Maji, M. Krishnan, Role of Si in Improving the Shape Recovery of FeMnSiCrNi Shape Memory Alloys. Phys. Proced. 10, 111(2010).

32. Matsumiya, Experimental study on sulfur removal from ladle furnace refining slag in hot state by blowing air. CALPHAD 35,627 (2011).

33. Kirindi, E. Guler, M. Dikici, Effects of homogenization time on the both martensitic transformations and mechanical properties of FeMn-Si-Cr-Ni shape memory alloy. J Alloy Compd 433,202 (2007).

34. Berns, W. Theisen, Combines steel and cast iron, which used to be treated in separate books. Ferrous Materials. Steel and Cast Iron (190 Springer 2008).

35. Suzuki, in Shape Memory Materials, (K. Otsuka,C.M. Wayman, eds.), Cambridge, pp. 145-147(1998). 
36. He, C. Jia, J. Meng, Influence of iron powder particle size on the microstructure and properties of Fe ${ }_{3} \mathrm{Al}$ intermetallics prepared by mechanical alloying and spark plasma sintering. Mat Sci Eng A 428, 314(2006)

37. Abdel Aziz A Khalil; Mahmoud F Zawrah, E. A. Saad, H A Badr, Synthesis and properties of hydroxyapatite nanorods, Interceram, 64 (2015) [8] 358-362

38. Hamzawy, A. A. El-Kheshen and M. F. Zawrah, Densification and Properties of Glass/Cordierite Composites, Ceramics Intentional, Volume 31, Issue 3, 2005, Pages 383-389.

39. Mohammed A. Taha, Amira H. Nassar, M.F. Zawrah, Effect of milling parameters on sinterability, mechanical and electrical properties of Cu-4 wt.\% $\mathrm{ZrO}_{2}$ nanocomposite, Materials Chemistry and Physics, Volume 181, 15 September 2016, Pages 26-32

40. M. S. Wahsh, R.M. Khattab and M.F. Zawrah, Sintering and technological properties of alumina/zirconia/nano TiO 2 ceramic composites, Materials Research Bulletin, Volume 48, Issue 4, April 2013, Pages 1411-1414.

41. F. Zawrah, Adel B. Shehata, E. A. Kishar, Randa N. Yamani, Synthesis, Hydration and Sintering of Calcium Aluminate Nanopowder for Biomedical Applications, Comptes Rendus Chimie, 14, pp611-618, 2011.

42. F. Zawrah, Mohammed A Taha, $\mathrm{H}$. Abo Mostafa, In-situ formation of $\mathrm{Al}_{2} \mathrm{O}_{3} / \mathrm{Al}$ core-shell from waste material: production of porous composite improved by graphene, Ceramics International, Volume 44, Issue 9, 15 June 2018, Pages 10693-10699

43. M. Khattab, A. El-Rafei, M. F. Zawrah, In-Situ Formation of Sintered Cordierite-Mullite Nano-Micro Composites by Utilizing of Waste Silica Fume, Materials Research bulletin, Volume 47, Issue 9, Pages 2662-2667 (2012).

44. Ayako Oyane, Hyun-Min Kim, Takuo Furuya,Tadashi Kokubo, Toshiki Miyazaki,Takashi Nakamura, Preparation and assessment of revised simulated body fluids, Journal of Biomedical Materials Research Part A 65(2) 2003, pp 188-195

45. Zhang, R. Sandström, "Fe-Mn-Si master alloy steel by powder metallurgy processing," Journal of Alloys and Compounds, 363 (2004), 194-202

46. Zhang, R. Sandstrom, K. Frisk, A. Salwen "Characterization of intermetallic Fe-Mn-Si powders produced by casting and mechanical ball milling," Powder Technology137 (2003), 139- 147.

47. Qian Zhang, X. G. Wang, Peng Cao, Wei Gao, Degradation behavior of a biodegradable Fe-Mn alloy produced by powder sintering, International Journal of Modern Physics: Conference Series Vol. 6 (2012) 774-779

48. Bin Chen, Kai-Yang Yin, Tian-Feng Lu, Bing-Yi Sun, Qing Dong, Jing-Xu Zheng, Chen Lu, Zhan-Chun Li, AZ91 magnesium alloy/porous hydroxyapatite composite for potential application in bone repair, Journal of Materials Science \& Technology 32 (2016) $858-864$

\section{Figures}




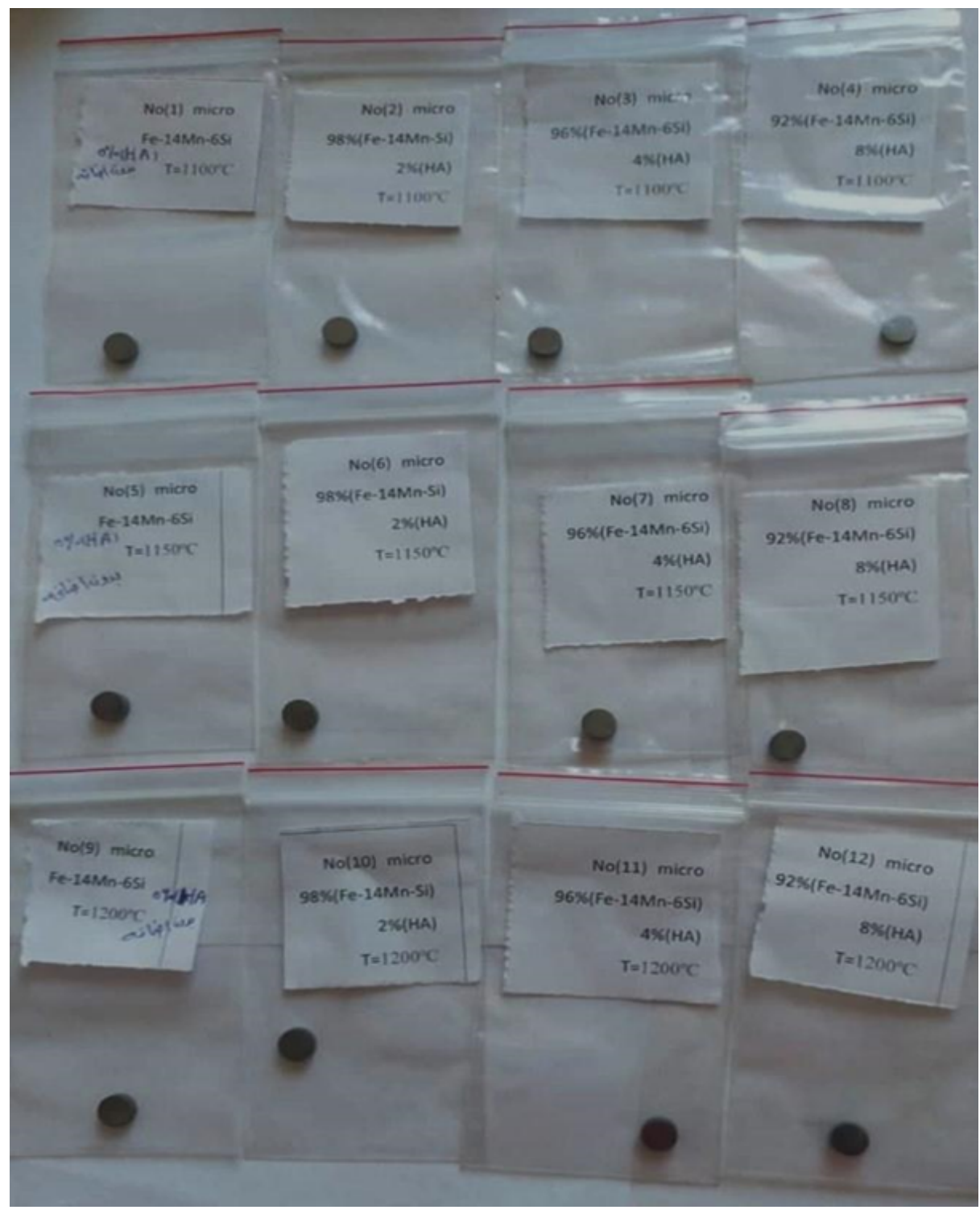

Figure 1

lamges of sintered composites

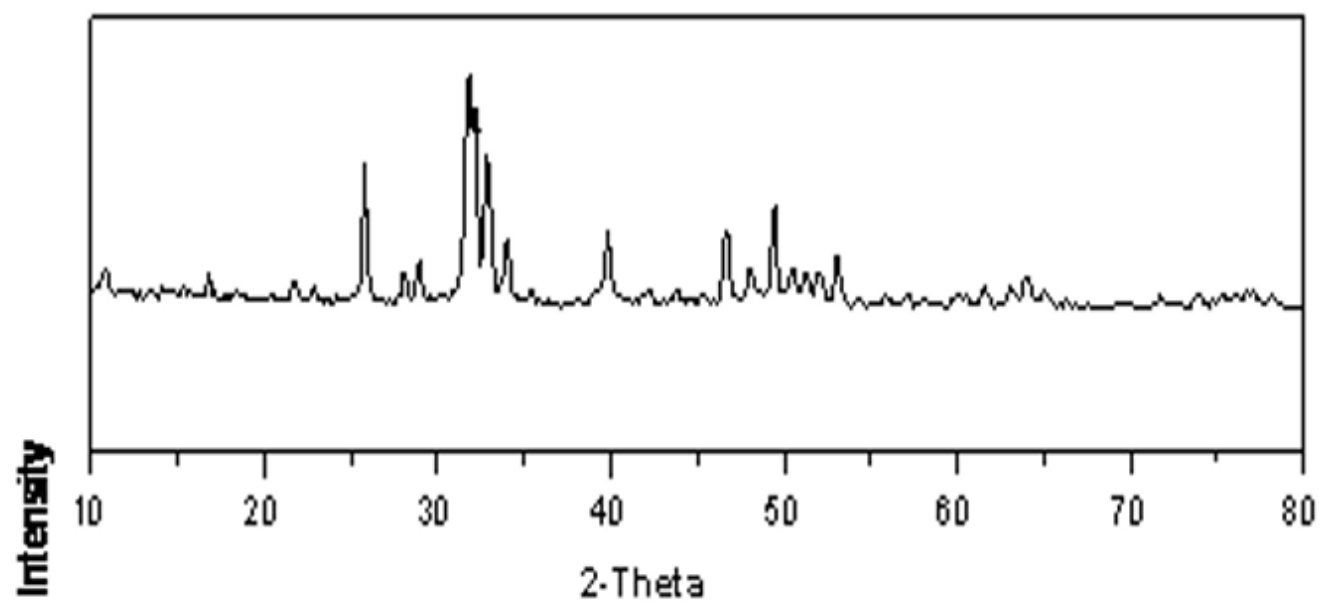

Figure 2

XRD patern of synthized hydroxyapatite 


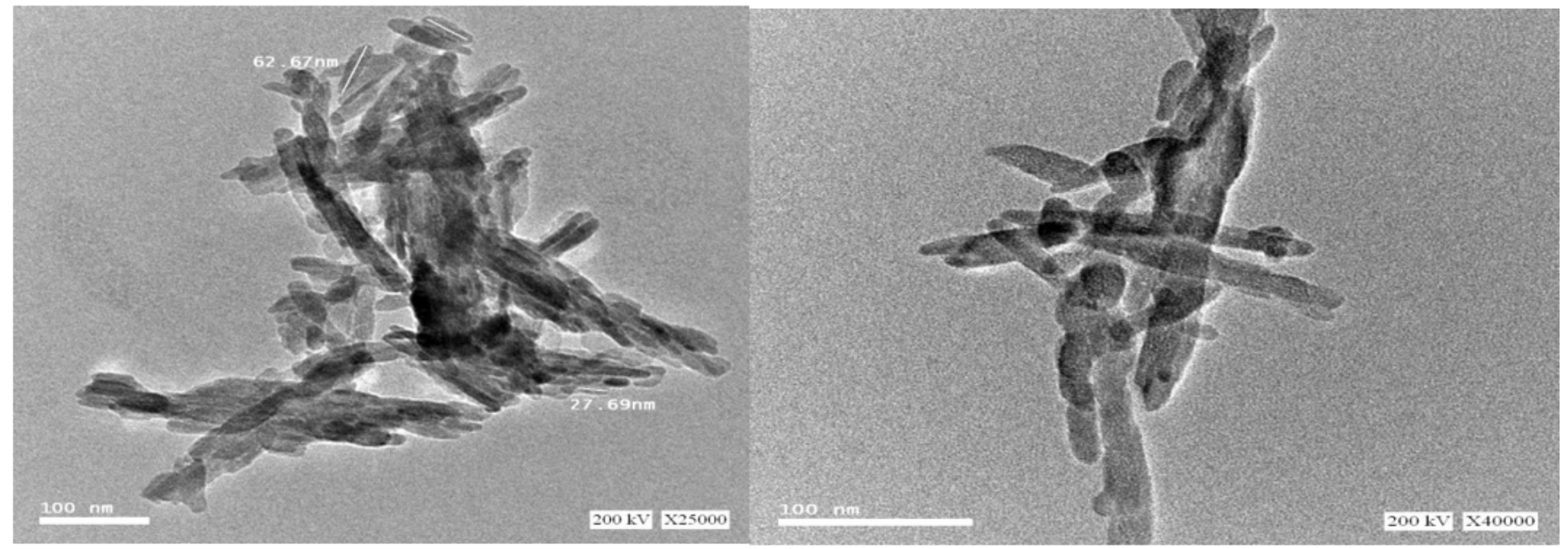

Figure 3

TEM images of synthesized hydroxyapatite

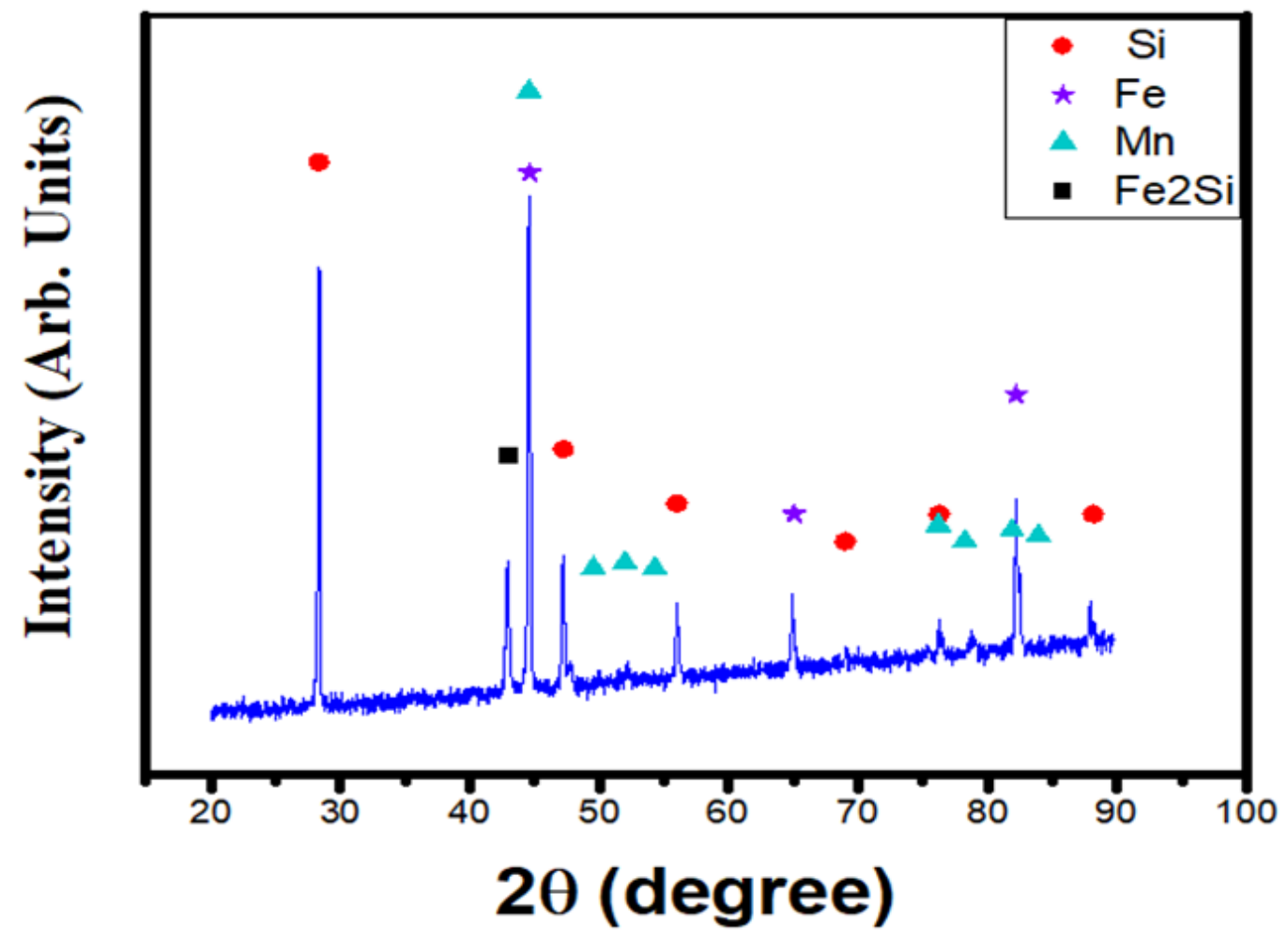

Figure 4

XRD patterns of Fe-14Mn-6Si 


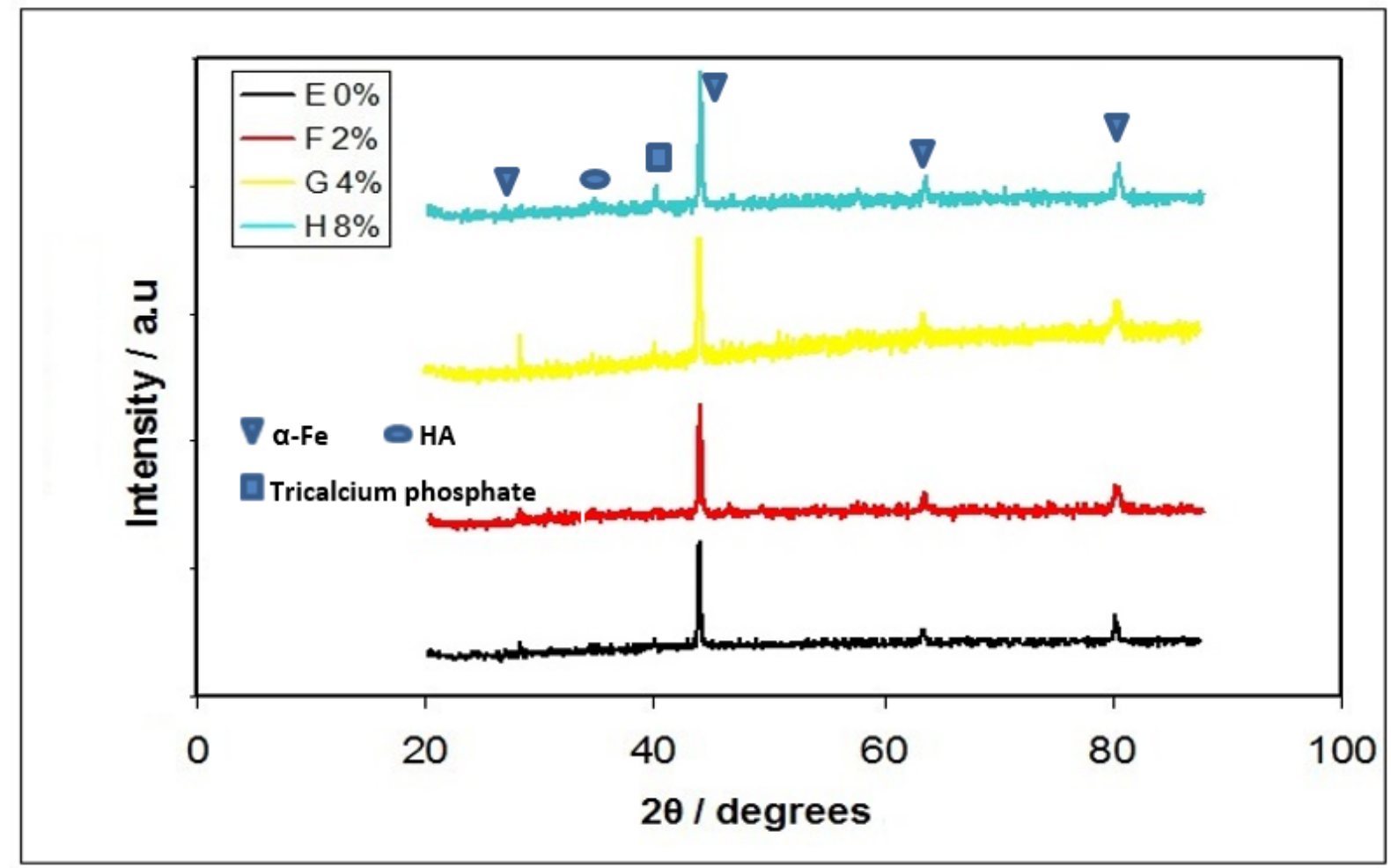

Figure 5

XRD paterns of composites sinterd at $1150 \circ \mathrm{C}$
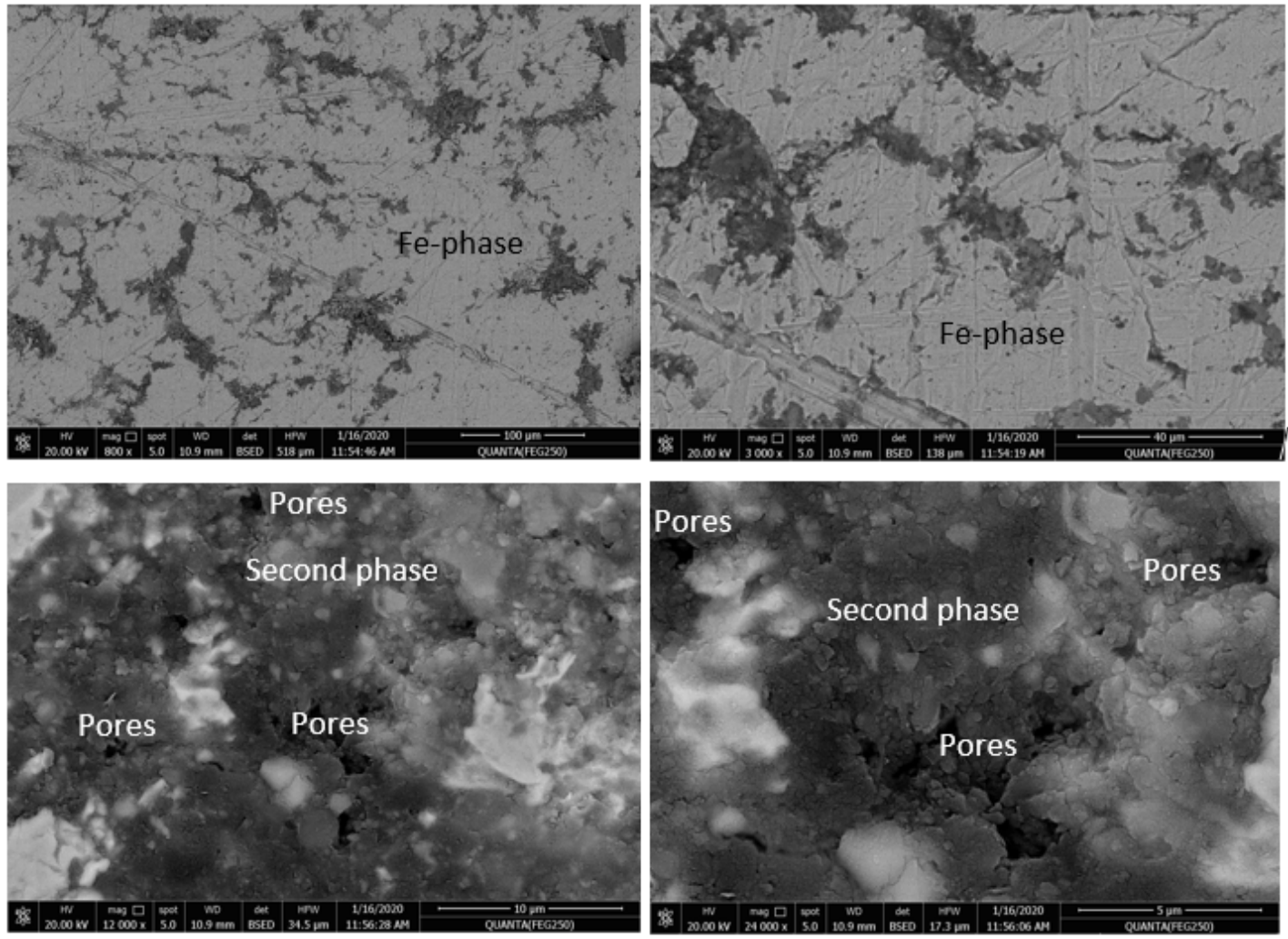

Figure 6

SEM images (different magnifications) of Fe-14Mn-6Si alloy sintered at 1150 oC 

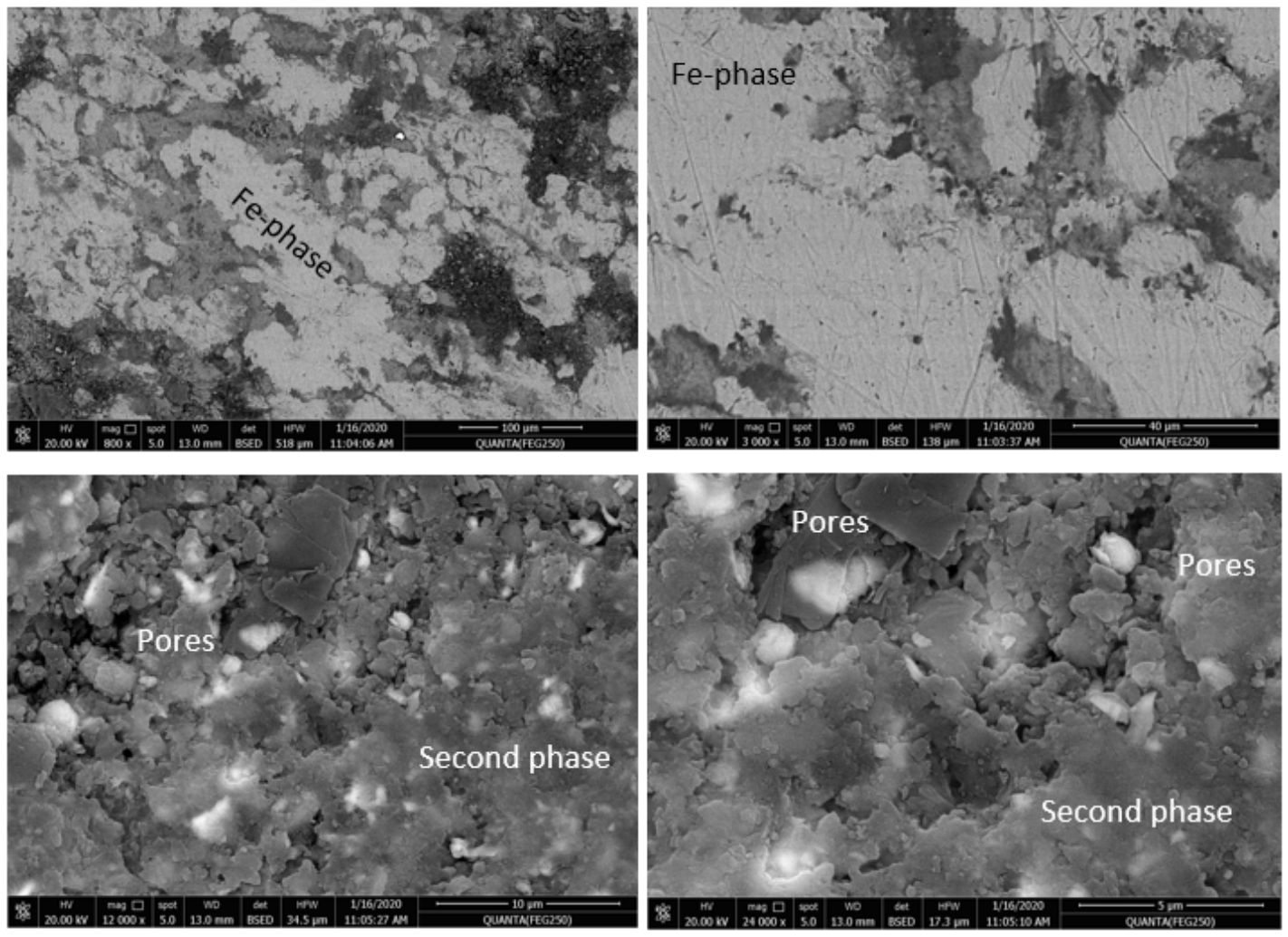

Figure 7

SEM images (different magnifications) of Fe-14Mn-6Si/8\%HA composite sintered at 1150oC

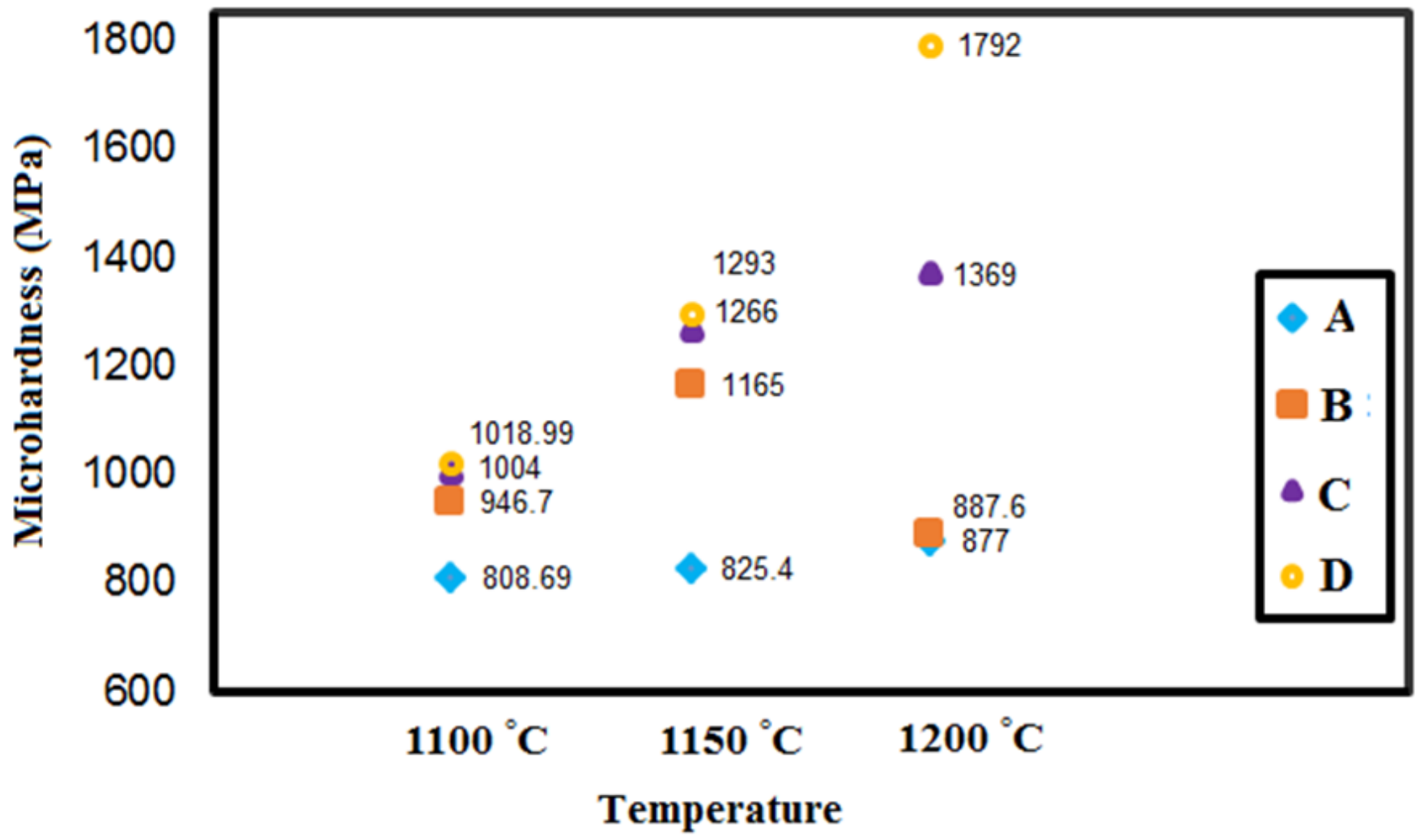

Figure 8

Micro hardness of sintered composites sintered at different temperatures for $2 \mathrm{~h}$ 

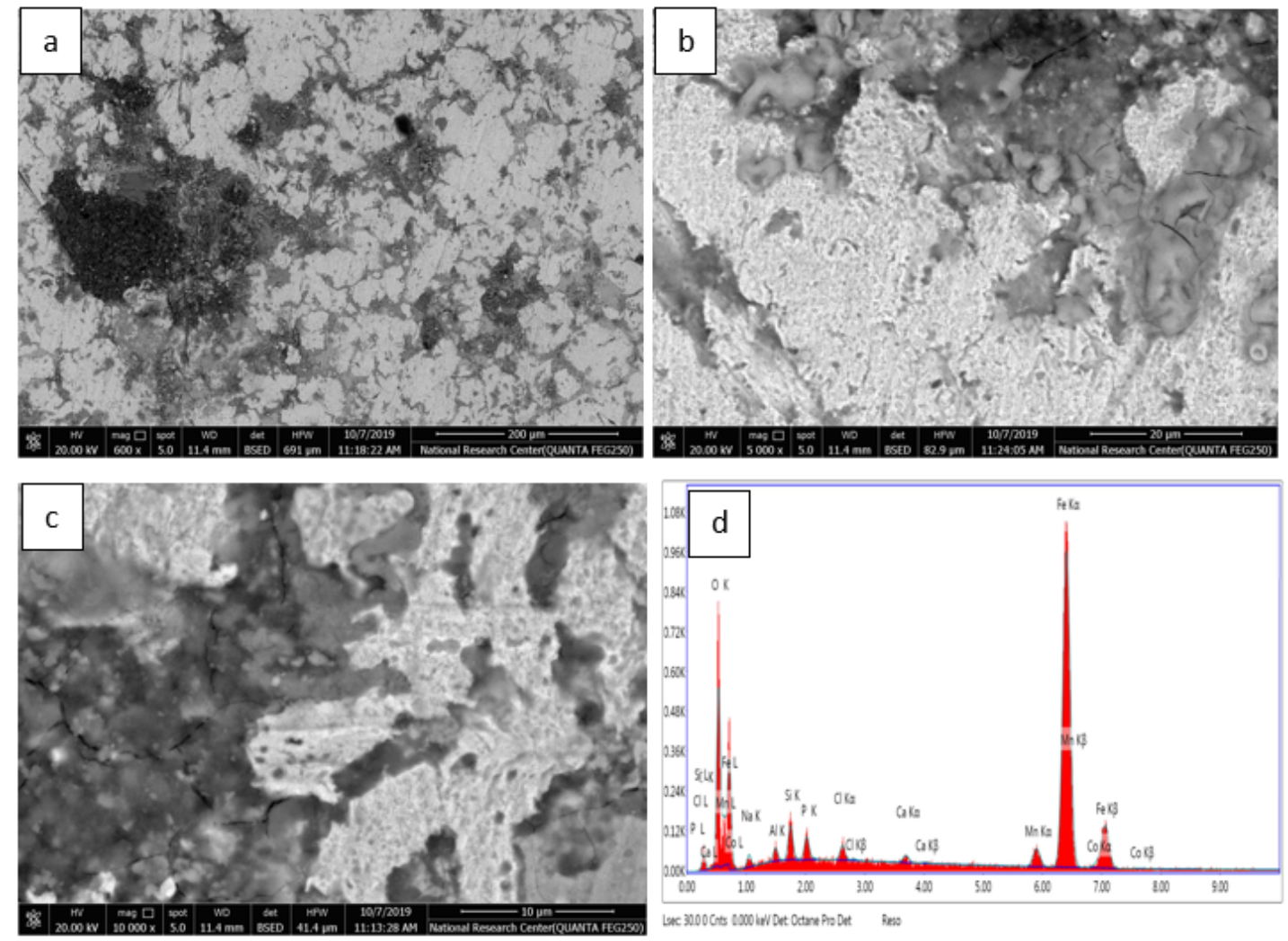

\section{Figure 9}

SEM images $(\mathrm{a}, \mathrm{b} \& \mathrm{c})$ and EDS analysis (d) of sintered Fe-Mn-Si after immersion in SBF for one month
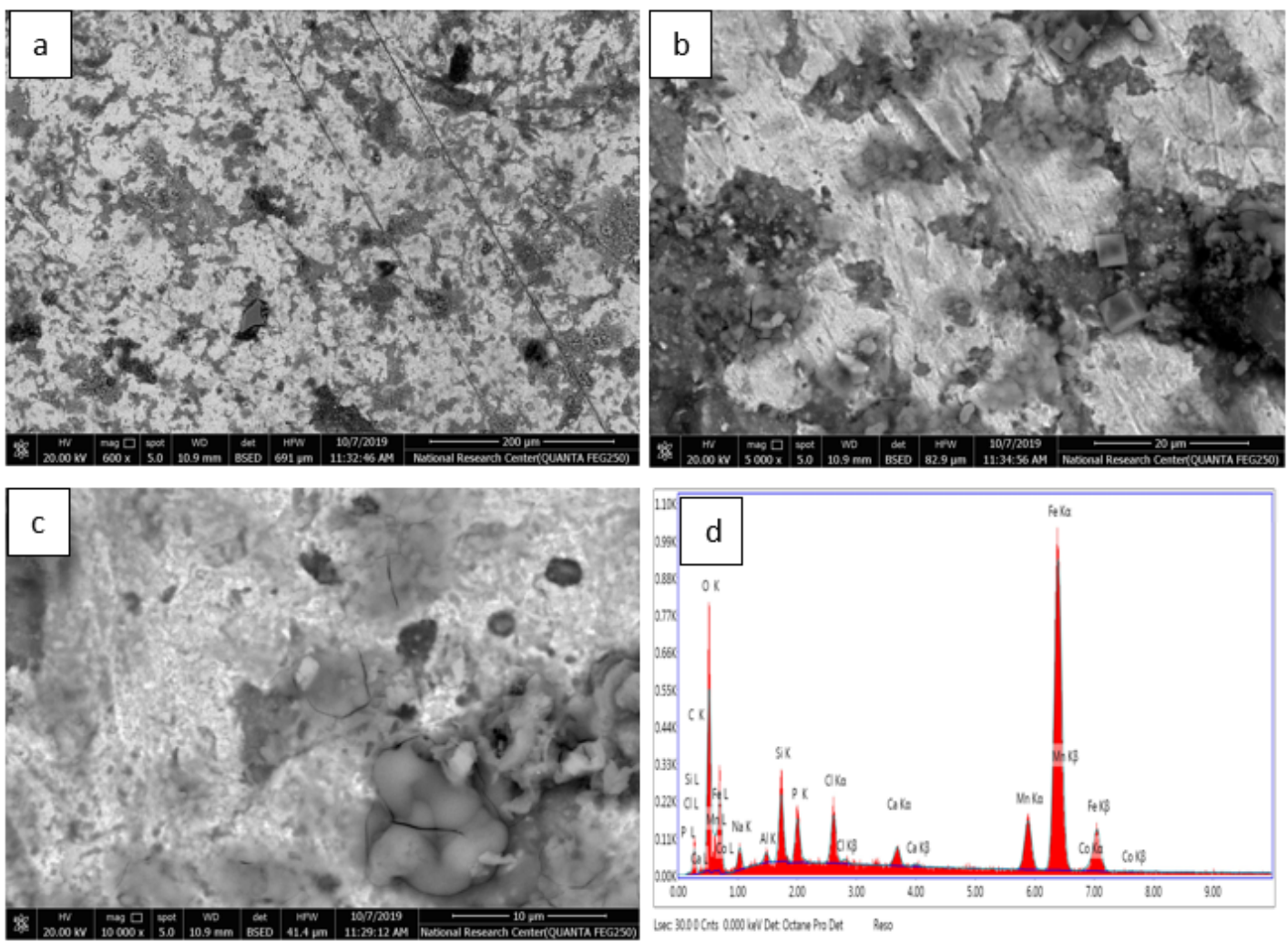

Figure 10

SEM images $(a, b \& c)$ and EDS analysis (d) of sintered $2 \%$ HA-containing composite after immersion in SBF for one month 

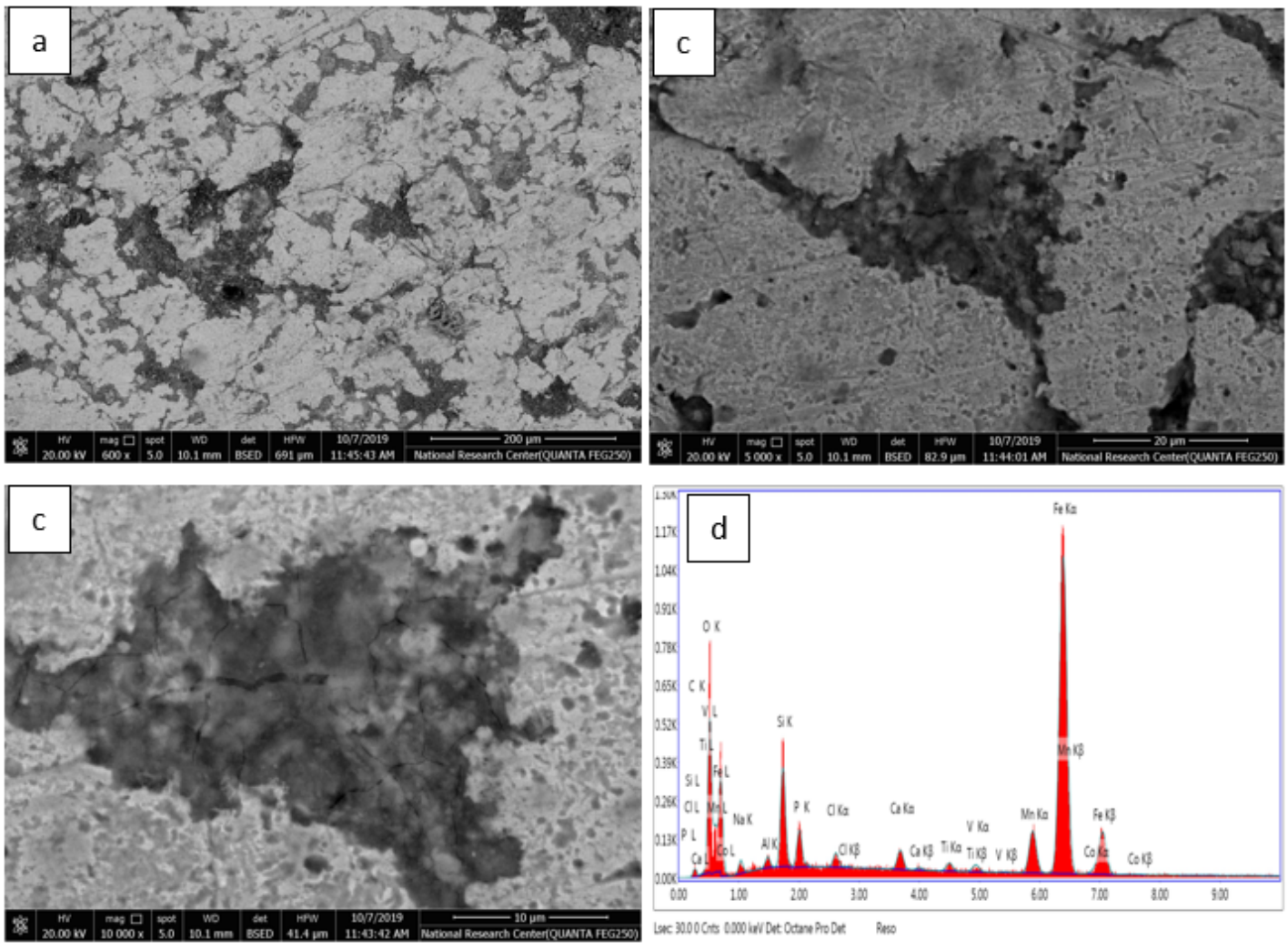

Figure 11

SEM images (a, b\&c) and EDS analysis (d) of sintered 4\% HA-containing composite after immersion in SBF for one month
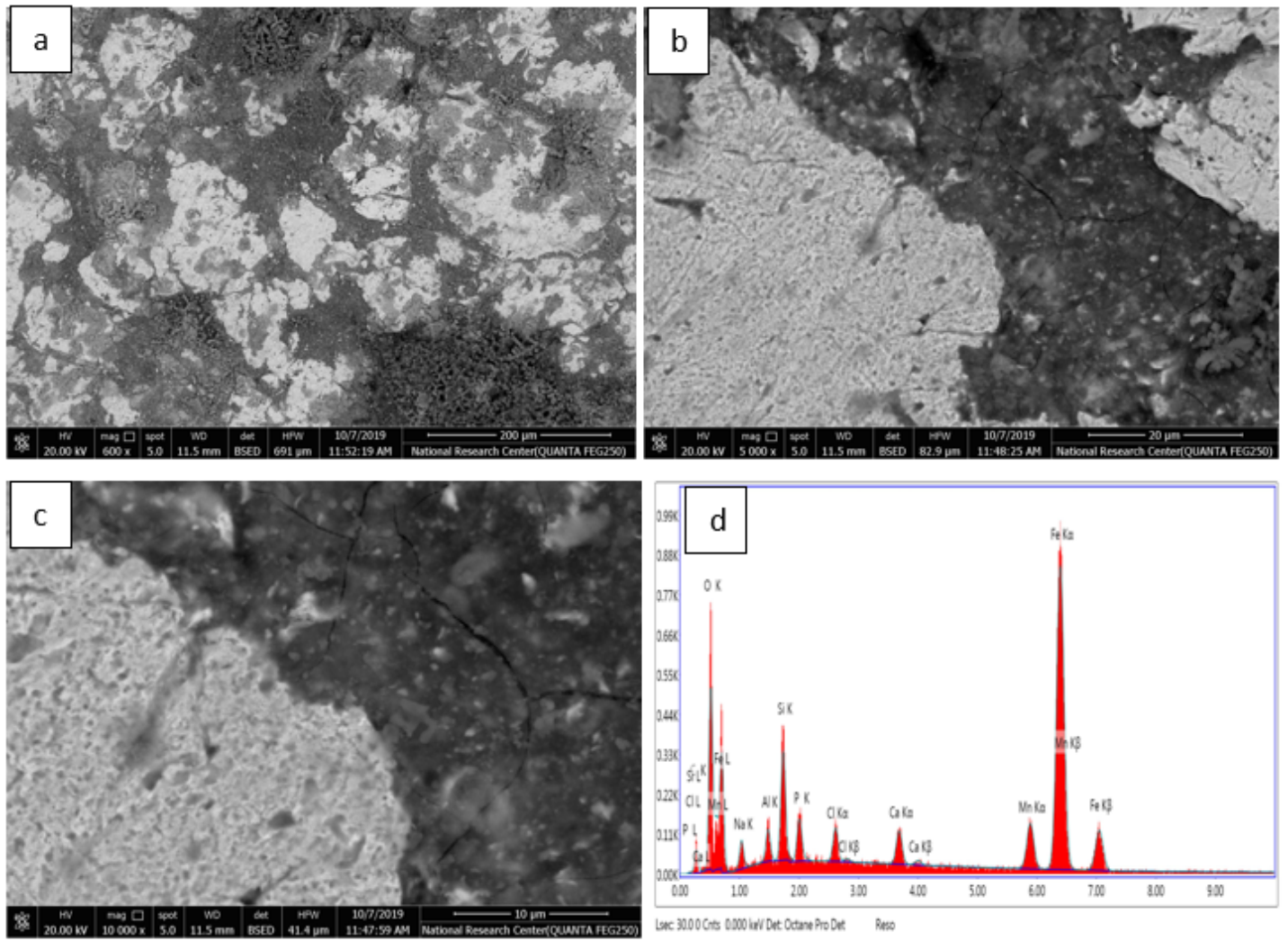

Figure 12

SEM images $(a, b \& c)$ and EDS analysis (d) of sintered 8\% HA-containing composite after immersion in SBF for one month 